\title{
Assess the Effectiveness of Self-Instructional Module on Knowledge Regarding Sarva Shiksha Abhiyan among Parent in Slum Area
}

\author{
Jaya Vijayrao Khandar, Sumit Rangari, Sapana Singh, Sneha \\ Somankar, Sonali Pawade and Nayna Tagade \\ Department Community Health Nursing Smt. Radhikabai Meghe Memorial College of Nursing, Datta Meghe \\ Institute of Medical Sciences (Deemed to be University), Sawangi (M), Wardha, Maharashtra, India. \\ Corresponding author email: jayakhandar@gmail.com
}

\section{ABSTRACT}

Universalization of education in India implies. Elementary education for all (classes I to VIII) and not for a selected few. This concept accept that education is the birth right of every child. This means that all children belonging to the rich and the poor living in town as will as rural area and in places which are accessible with difficulty have to be provided with facility for elementary education. It is accepted in UN's declaration of human rights and children rights it is universally accepted that the universalization ' of the elementary education is the true index of the general economic political and social development of a country. To assess the level of knowledge regarding Sarva Shiksha Abhiyan among parents.2) to evaluate the effectiveness of self instruction module regarding Sarva Shiksha Abhiyan among parent in slum area.3) Find out the association between the demographical variable with the post test knowledge of Sarva Shiksha Abhiyan among parent in slum area. There is a significant difference between the score of pre-test and post-test knowledge of Sarva Shiksha Abhiyan among the slum parents. Study design is pre experimental one group pre test and post test design participant of the study was 100 parent selected slum area of Wardha.Non probability convenient sampling technique study conduct in selected area of Wardha city. The level of knowledge among parents in the slum area was concerning Sarva Shiksha Abhiyan. That 44\% of parents had poor knowledge score, 45\% had average knowledge score and 11\% had good knowledge score. The minimum score for pretest knowledge was 1 and the maximum score for pretest knowledge was 12 . Mean knowledge score in pretest was $6.35 \pm 2.95$ and mean percentage of knowledge score in pre test was 25.40 \pm 11.82 .the level of post-test knowledge level among parents in the slum area was concerning Sarva Shiksha Abhiyan that 57 per cent of parents had very good knowledge score level and 43 per cent outstanding knowledge score level. Minimum score for knowledge in posttest was 16, and maximum score for knowledge in posttest was 24.Mean post-test knowledge score was $20.09 \pm 1.89$ and average post-test knowledge score was $80.36 \pm 7.56$. Self instructional module significantly have proved their improvement in knowledge regarding Sarva Shiksha Abhiyan for selected slum area among parents data analysis show that their noticeable difference between pre- and post-test.

\section{KEY WORDS: SELF INSTRUCTIONAL MODULE, SARVA SHIKSHA ABHIYAN, PARENT, SLUM AREA}

\section{INTRODUCTION}

Background: India is one of the larger democratic countries in the world. For the development of the every

Biosc Biotech Res Comm P-ISSN: 0974-6455 E-ISSN: 2321-4007

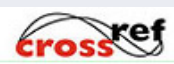

Identifiers and Pagination

Year: 2021 Vol: 14 No (9) Special

Issue Pages: $364-369$

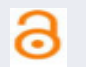

c) creative
This is an open access article under Creative

Commons License Attribn 4.0 Intl (CC-BY).

DOI: $h t t p: / / d x$.doi.org/10.21786/bbrc/14.9.67

\section{Article Information}

Received: $05^{\text {th }}$ June 2021

ccepted after revision: $20^{\text {th }}$ July 2021 nation the quality basic education is sin qua non. So the human beings without education become an animal. education is the is the 21 century a nation ability to convert knowledge into wealth and social and good thought the process of Enovation is going to determine its feature. The future of the nation is the Hand of young generation why the quality and overall education at primary level is very essential.

There are two goals of Sarva Shiksha Abhiyan (SSA) that universal enrollment and universal retention. Enrollment and Retention in elementary education system 
depends upon various educational and socio-economic variables.

The Sarva Shiksha Abhiyan, among other things, seeks to promote Community participation in school education. Child are active youngster who receive decreasing amount of supervision from the parent and other adults All younger kids can be rebellious stubborn and impulsive from time to time, which is perfectly normal in the span of school age. And sense of taste is fully mature prior to the school year and they have more independent. Children attempt to master new motor skill are it past of organizational teaching learning process for student.

The teachers are pillars of education system. Qualitative retraining input leading to reading to value addiction amongst teacher is a way to enhance quality teaching learning process. Teacher training is continuing process under Sarva Shiksha Abhiyan. Teachers have a broader roll and crucial responsibility in achieving Sarva Shiksha Abhiyan. It is quite important to target the teacher. Unless the teacher prepared them self to adopt the new teaching pedagogies no improment it the exiting standard of education being imparted in our school can be achieve. It is the necessary in service / freshly recruited teacher should be organized at district level India made a Constitutional commitment to provide free and compulsory education to all children up to the age of 14 nearly sixty years ago. The goal, which was expected to be achieved by 1960 , remains elusive, even now. Yet, one has to admit that developments in recent years have had significant impacts on the situation, raising the hope that universal basic education could be a reality within a reasonable period of time. Three factors seem to be making a distinct difference in the growth trajectory of elementary education in the country.

This case study was done Sarva Shiksha Abhiyan (SSA) in India, the largest basic education programme in the world, assesses the significance of foreign aid for achieving increased access to elementary education from 2002 to 2010, particularly for the most disadvantaged. It reviews the practical experience of India and its development partners in jointly developing and implementing a national education programme and how greater alignment of external assistance with the Government of India's national policy for achieving universal elementary education was brought about, thus promoting country leadership and harmonizing donor practices for effective aid delivery in line with the principles of aid effectiveness set out in the Paris Declaration (signed by the members of the Development Assistance Committee (DAC) of the OECD and representatives of the developing countries in 2005). The paper draws on documentation about, and experience of SSA design and implementation to establish, through analysis, a picture of how foreign aid principally from three development partners is being used effectively to support India's own policy and strategy for universalizing elementary education.

The case shows that the development partners are playing an important role and that external support for elementary education in India is organised in a unique and effective way and contributed to increased access to basic education, particularly in the populous north of the country. Universalizing basic schooling means free tuition. Free education in some of the progressing countries It is widely recognized in the decline of the UN in human rights and children's rights that the universalization of primary education is the true measure of the overall political and social development of a country means no free book fees And free stationary midday Free school transport and meals but this is True to that in developing countries such as India. It was Unable to access all these services at this staging Freebies tuition fees at no cost of course education. Further facilities are also provided on a selective basis.

\section{MATERIALS AND METHODS}

Quasi -Experimental research design (One Group PreTest Post -Test Design) was chosen because this research study aimed at evaluating the effectiveness of the selfeducation module in improving the awareness of Sarva Shiksha Abhiyan selected among parents in the slum region. Research design pre-experimental, one group and pre-test and post. Target population was parents in slum area of selected Wardha city. Sampling technique was non probability convenience sampling sample size was 100 parents of selected slum area. Sample size calculation $\mathrm{N}=\mathrm{x} 2$.N.P (1-P) / c 2 (N-1) + x 2.P. (1-P) X2 = Chi-square value for 1 degree of freedom at some desired probability level. Where's N=No of parents $=135$

$\mathrm{X}^{2}=$ Chisqnare value at $1 \mathrm{df}$ for some desired probability level $=3.84, \mathrm{P}=50 \%$ Proportion $=0.50, \mathrm{C}^{2}=$ Desiredprobabilitylevel $=5 \%=0-05 \mathrm{~N}=3.84 \times 135 \times 5.50 \times$ $0.50 \div(0.05 \mathrm{z} \times 134)+(3.84 \times 0.5 \times 0.50)=100.7, \mathrm{~N}=100$ parents needed in the study Tool use for this study was structured questionnaire for assess the effectiveness of the self education module on parental knowledge of Sarva Shiksha Abhiyan in the slum region. Assessment of knowledge based on criteria measurement (excellent, good average, poor.)

\section{Inclusion Criteria}

- Slum area parents who are eager to take part in the research. (A lack of awareness of sarva Shiksha Abhiyan among slum parents and lack of understanding the programme development. Surrounding or home environment is one of the important factors influencing the educational.)

- Slum area parents who are available at the time the data are collected.

- Slum area parent who can understand and write Marathi language.

\section{Exclusion Criteria}

- Slum area parents

- Who have already attended similar type of study?

- Parents who are involved in sarva Shiksha Abhiyan project. 
A tool was devised through several steps of item education religion pilot testing of the tool and validating the tool. The content validity was determined after the opinion of 10 experts' in the field of community health nursing and child health nursing Tool validation included measurement of inter-observer reliability; and generation of criterion related, construct related and content related validity. The tool was later revised by English-language expert and then translated into Marathi language by language experts without altering the tool's meaning. This is true and appropriate for Sarva Shiksha Abhiyan. The Institutional Ethical Committee of the Datta Meghe, Institute of Medical Sciences,' Deemed to be University sanctioned approval for conducting the research study was obtained. The findings were summarized by concentrations and percentages, categorically. The program used in the study was SPSS 24.0 and the edition of Graph Pad Prism 7.0 and $p<0.05$ is regarded as a degree of significance.

\section{Preparation of the Tool}

A tool or an instrument is a formal written document used to collect and record information, the researchers prepared the tool for this study after extensive literature review. Description of the Tool-A structure questionnaire consists of two sections

Section I and Section II.

\section{Section I}

It is consisting of demographic characteristics regarding the parent in slum area i. e. Age, gender education, occupation, monthly income, previous information about Sarva Shiksha Abhiyan, Sarva Shiksha Abhiyan sources.

\section{Section li}

The assessment of knowledge regarding sarva Shiksha Abhiyan for selected parent in the slum area is comprised of 25 multiple choice questions.

Score: - For the correct answer SCORE 1 was given, Score 0 for wrong answer, Knowledge ranked from poor knowledge to excellent, scoring-based knowledge.

\section{Methods for of Data Collection}

For the present study the validated tool was used structured questionnaire. The tool was in Marathi. Structure questionnaire contained 25 multiple choice questions. Data was collected within 15 day group members pre-test data collection was followed by knowledge. The data was collected within 2 weeks.

\section{Process of Data Collection}

- The following timetable for data collection was followed;

- The subject matter was clarified regarding the nature and intent of the analysis

- They were assured that the data was confidential

- The subject was given questionnaire selfadministered

- It look $30 \mathrm{~min}$ fill the per test

Structure the subject was given the same day as the teaching programme after pre-test any queries raised by the subject were clarified after the structure programme

Post test data collection with the same questionnaire was done 7 days.

\section{Content Validity}

The tool was given to 7 days in order to obtain validity of the material. Experts who include one from the statistics department, one from the English department and five from the Community Health Nursing department. After receiving expert opinions and consulting from the guide, some modifications have been made to frame the item and the same has been incorporated into the tool.

\section{Informability}

Reliability is the instrument's capability to produce reproducible results. (Laura 1995) Tool reliability is an important criterion for the efficiency and accuracy evaluation. It is the degree of consistency it measures the attribute with, it should be measured.

\section{Ethical Aspects}

- $\quad$ The research problem was approved by the research committee

- Information about the study given to participant

- Permission obtained from the concerned of the selected city /village

\section{Statistical Analysis}

The Study Was Conducted among 100 parents of slum area. The present study was used to test the effectiveness of the self-education module on Sarva Shiksha Abhiyan awareness among slum parents. For data collection a standardized questionnaire was used to gather the information ratings. The percentage of wise parent distribution in terms of their demographic characteristics. A convenient sample of 100 subjects was drawn from the study population, who were from selected slum area. The data obtained to define the sample characteristics, including age, sex, educational level, job, monthly family income, knowledge about Sarva Shiksha Abhiyan and source of knowledge respectively.

\section{RESULTS}

Results were expressed as in this study $36 \%$ of the parents in the 30-35 age group, 23 per cent in the 36-40 age group, 41 per cent in the 41-50 age group and above. Education of parents $40 \%$ of the parents were educated 
up to primary standard, $41 \%$ up to secondary standard, $13 \%$ were illiterate and only $6 \%$ of the parents were graduates. Occupation of parents $10 \%$ of the parents were farmers, 24\% of them were housewife, 61\% of them were daily wagers and 5\% of them were doing job. Monthly income (Rs) 31\% of the parents had monthly family income of 4001-6000 Rs, 22\% had between 60018000 Rs and $47 \%$ of them had monthly family income of 8001-10000 Rs. source of knowledge about Sarva Shiksha Abhiyan the parents had information from mass media, $15.20 \%$ had from friends and $60.90 \%$ of the parents had information from neighbor. The level of knowledge among parents in the slum area concerning Sarva Shiksha Abhiyan. The level of knowledge score is divided under following heading of poor, average, good, very good and excellent.

Table 1. Distribution of parent according to their
demographic characteristics

\begin{tabular}{|c|c|c|}
\hline $\begin{array}{l}\text { Demographic } \\
\text { Variables }\end{array}$ & $\begin{array}{c}\text { Parents } \\
\text { No. (N-100) }\end{array}$ & $\begin{array}{l}\text { Percentage } \\
(\%)(N-100)\end{array}$ \\
\hline \multicolumn{3}{|c|}{ Age(yrs) } \\
\hline 30-35 yrs & 36 & 36 \\
\hline $36-40$ yrs & 23 & 23 \\
\hline $41-50$ yrs and above & 41 & 41 \\
\hline \multicolumn{3}{|c|}{ Gender } \\
\hline Male & 58 & 58 \\
\hline Female & 42 & 42 \\
\hline \multicolumn{3}{|c|}{ Educational Level } \\
\hline Primary & 40 & 40 \\
\hline Secondary & 41 & 41 \\
\hline Illiterate & 13 & 13 \\
\hline Graduation & 6 & 6 \\
\hline \multicolumn{3}{|l|}{ Occupation } \\
\hline Farmers & 10 & 10 \\
\hline Housewife & 24 & 24 \\
\hline Daily Wages & 61 & 61 \\
\hline Job & 5 & 5 \\
\hline \multicolumn{3}{|c|}{ Income of the family } \\
\hline 4001-6000 Rs & 31 & 31 \\
\hline 6001-8000 Rs & 22 & 22 \\
\hline 8001-10000 Rs & 47 & 47 \\
\hline \multicolumn{3}{|c|}{ Knowledge regarding Sarva Shiksha Abhiyan } \\
\hline Yes & 46 & 46 \\
\hline No & 54 & 54 \\
\hline \multicolumn{3}{|c|}{ Source of knowledge } \\
\hline Mass Media & 11 & 23.9 \\
\hline Friends & 7 & 15.2 \\
\hline Neighbour & 28 & 60.9 \\
\hline
\end{tabular}

Assessment of pre-test level of knowledge regarding sarva Shiksha Abhiyan among parents that 44\% of parents had poor knowledge score, 45\% had average knowledge score and 11\% had good knowledge score. The minimum score for pretest knowledge was 1 and the maximum score for pretest knowledge was 12 .
Mean knowledge score in pretest was $6.35 \pm 2.95$ and mean percentage of knowledge score in pre test was $25.40 \pm 11.82$.

Figure 1: Assessment of level of existing knowledge of Sarva Shiksha Abhiyan

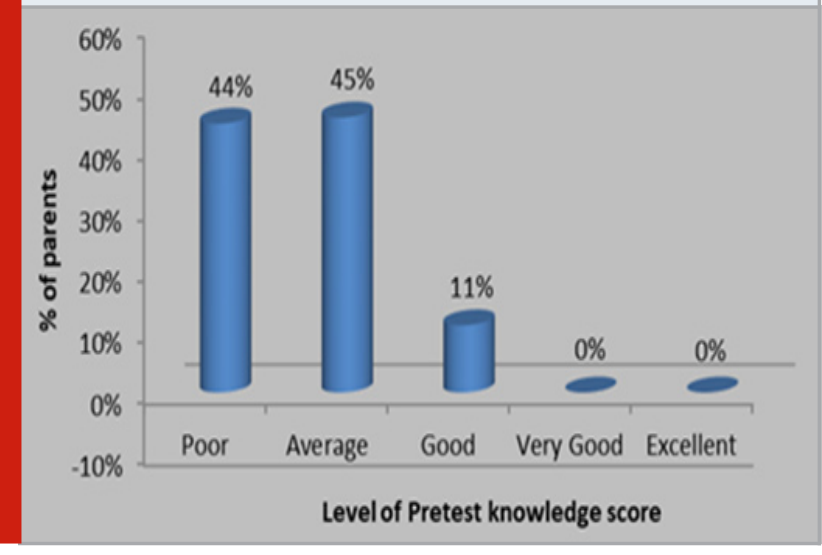

Figure 2: Assessment of level of knowledge of Sarva Shiksha Abhiyan after intervention

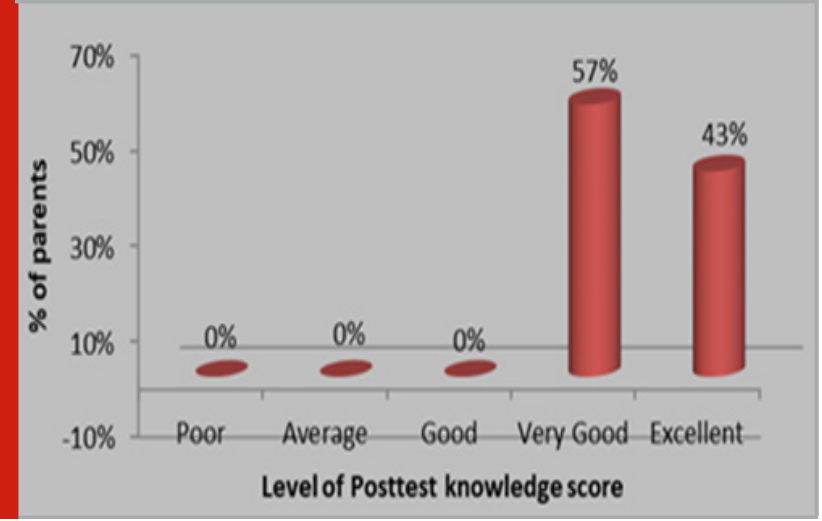

Assessment of posttest knowledge score among parents regarding sarva Shiksha Abhiyan that 57 per cent of parents had very good knowledge score level and 43 per cent outstanding knowledge score level. Minimum score for knowledge in posttest was 16, and maximum score for knowledge in posttest was 24. Mean post-test knowledge score was $20.09 \pm 1.89$ and average post-test knowledge score was $80.36 \pm 7.56$ The pre-test and posttest awareness scores on Sarva Shiksha Abhiyan While, standard deviation and mean differential values are compared and the paired student evaluation is applied at 5 per cent meaning point. For $n=100-1$ i.e. 99 degrees of freedom the tabulated value was 1.98. The measured value ' $t$ ' i.e. 37.44 Are significantly higher than the table value at a sense point of 5 percent for parents ' overall information score which is statistically appropriate. It is therefore interpreted statistically that the self-instruction module on parental awareness of Sarva Shiksha Abhiyan was successful. Thus the H1 is accepted.

\section{DISCUSSION}

Effectiveness of self-instructional module on knowledge 
regarding sarva Shiksha Abhiyan among parent in slum area. The objective was to assess the level of knowledge regarding sarva Shiksha Abhiyan among parents. To evaluate the effectiveness of self instruction module regarding sarva Shiksha Abhiyan among parent in slum area. Find out the association between the demographical variable with the post test knowledge of sarva Shiksha Abhiyan among parent in slum area.

The study was reveals that the Sarva Shiksha Abhiyan programme aims to ensure elementary education for all including five years of primary education and eight years of schooling for all children. The Sarva Shiksha Abhiyan focuses on community ownership and the village education plans proposed in construction with Panchayati Raj Institutions (PRIs). The central focus in the implementation of the programme is community ownership and their participation in school related activities to bring more relevance in the field of primary education.

The study was undertaken to evaluate the various parameters of Sarva Shiksha Abhiyan (SSA) in district Shopian in Kashmir valley. The parameters were to study the number of primary schools opened under SSA in all educational zones of district Shopian, pupil teacher ratio, total enrollment, Midday meal scheme, total number of EGS centres, training facilities, infrastructure facilities in terms of Classrooms, Principals room, Staff-room, Benches, Mating, Black boards, Chairs etc. To assess the role of VEC's \& to study the progression in enrollment in these schools, with effect from the implementation of the scheme (2002). The sample consisted of all the 204 SSA schools of district Shopian. Self constructed information blank and check list were used for the collection of data and percentage statistics was used for the analysis of data. The results of the study highlight that SSA has opened 204 schools upto June 2012 in all the 04 educational zones of district Shopian with total enrolment of 7106 .

A total no. of 395 teachers have been appointed making over all pupil teacher ratio (PTR) of 1:17. There has been overall $79.2 \%$ progression in enrollment from 2002 to June 2012. Although government is painting a rosy picture on the implementation of centrally sponsored schemes but still a percentage of $55 \%$ \&t $64 \%$ of SSA schools of concerned district are without toilet $\&$ drinking water facility respectively. All the Education Guarantee Scheme (EGS) centres were elevated to normal SSA primary schools and majority of them are running in single The Sarva Shiksha Abhiyan, among other things, seeks to promote community participation in school education. The programme has completed its first phase of five years of implementation. This article evaluates the working of the school education management committee in a tribal area of East Godavari district of Andhra Pradesh. It shows that community participation in improving education is negligible and that members of the SEMCs have limited awareness of the SSA.

This survey was done on Sarva Shiksha Abhiyan schools in Sahibganj district of Jharkhand reveals that the SSA, despite its emphasis on decentralization and inbuilt flexibilities, is not making much headway in a socially and economically differentiated setting. This reflects a perception of poor quality of the SSA and also a lack of understanding by the programme of social relations and structural constraints.

Acharya,Prasantakumar And Behera, Manoranjan (2004)The end of November 2003, the progress on civil work and had been very slow especially due to late release of funds, inadequate monitoring and lack of district level convergence of SSA with other allied development schemes. But remarkable progress was made by Orissa primary education programme authority (OPERA) in organizing teachers training programme both at the state and the district level. Nearly 70\% EGS (Education guarantee scheme) this is a remarkable achievement. The progress in the opening of alternative and innovative education centres (AIE) was very unsatisfactory.

\section{CONCLUSION}

Pre test Knowledge regarding Sarva Shiksha Abhiyan among the parent was that $44 \%$ of parents had poor knowledge score, 45\% had average knowledge score and $11 \%$ had good knowledge score. Assessment of post test knowledge score among parents regarding sarva Shiksha Abhiyan that 57 per cent of parents had very good knowledge score level and 43 per cent outstanding knowledge score level. Effectiveness of self instructional module has enhanced the knowledge regarding sarva Shiksha Abhiyan among parent in slum area. Hence the self instructional module is effective, appropriate and feasible it can be used in different setting to improve the knowledge of parents.

\section{REFERENCES}

Ambert, A.M., 2020. Parents, children, and adolescents: Interactive relationships and development in context. Routledge.

Bordhan, S., 2014. Parental attitude towards schooling of their children. Journal of All India Association for Educational Research Vol, 26(1).

Chanana, K., 2003. Gender Inequality in Primary Schooling in India: The Human Rights Perspective. Education, Society and Development: National and International Perspectives, pp.197-219.

Jenkins, T.N., 2014. The evolution of British airborne warfare: a technological perspective (Doctoral dissertation, University of Birmingham).

Koul, L. (1984): Methodology of Educational Research. Vikas Publishing House Pvt.Ltd.New Delhi.

Kumar, G.M., Prasad, J. and Verma, J.P., 2013. Statistical analysis of socio-economic variables responsible for wastage in elementary education in Rajasthan, India. International Research Journal of Social Sciences, 2(6), pp.1-6..

Rao, V.S., 2009. Lack of community participation in the Sarva Shiksha Abhiyan: A case study. Economic and 
Political Weekly, pp.61-64.

Rao, N., 2009. Structural Constraints in Sarva Shiksha Abhiyan Schools. Economic and Political weekly, pp.1720.

Samal, R., 2012. Parents' attitude towards schooling and education of children (Doctoral dissertation).

Singh, J., 2020. Interventions in the Field of Education
During Conflict Situations of Kashmir. Studies in Indian Place Names.

Tabesh, H., Saki, A. and Pourmotahari, F., 2013. Comparing Two Formulas of Sample Size Determination for Prevalence Studies.

Tomaševski, K., 2008. The State of the Right to Education Worldwide: Free or Fee?:: 2006 Global Report (pp. 1953). Brill Sense. 